\title{
Atención clínica en los márgenes finales de la vida
}

\author{
Clinical care in the final margins of life
}

\author{
Arturo Fuentes Varela \\ Médico. Experto en Bioética Sanitaria. Ex-presidente del CEA del CHUO. Ex-presidente de la Comisión de Deontología del ICOMOU
}

En la edición de septiembre de 1981, la revista "Galicia Clínica" tuvo la deferencia de acoger mi primera publicación "Particularidades de la fiebre tifoidea en nuestra área", dedicada al estudio de dicha patología en el mundo de la pediatría; y cuarenta años después, tras mi paso por el Comité de Ética Asistencial del CHUO (Complexo Hospitalario Universitario de Ourense) y de la Comisión de Deontología del ICOMOU (llustre Colegio Oficial de Médicos de Ourense), me invitan a reflexionar sobre un aspecto de las ciencias de la salud que implica, no sólo pericia biológica, sino también mirada a los valores personales.

Los profesionales dedicados al mundo de la salud desarrollan instintos empáticos, útiles para mejorar la percepción en la calidad de vida de los pacientes, ya sea por poseer y cultivar cualidades personales para acoger un tipo determinado de modelo profesional al servicio de la salud de las personas y las poblaciones, ya sea por el genérico conjunto de características que definen la nombrada "vocación profesional". En base a ello, no sólo curamos las enfermedades ad integrum en ocasiones, sino que acompañamos con diligencia, eficiencia y compasión esperanzada a los individuos cuya patología reconocemos no poder curar a la altura de los saberes de la ciencia médica del momento, o que por conocimiento y experiencia de la historia natural de los procesos morbosos, entendemos que son susceptibles de acompañamiento para mejorar sus niveles de calidad de vida y no de curación.

Así, los profesionales del mundo de la salud ejercemos de catalizadores, junto al enfermo, para lograr mayores cotas de "vida vivible" aún en el seno de procesos morbosos que, abandonados a sí mismos, conllevan quebranto, dolor, angustia, desesperanza, soledad,...; pero capaces de ser transformados en periodos de vida gozosa, agradecida, esperanzada, yugulados, con menos o sin dolor, con menor sufrimiento, ... si son acompañados por profesionales idóneos, preñados de ciencia útil para aliviar y de humanidad compasiva para mantener la esperanza.
Digo que los profesionales sanitarios podemos actuar de catalizadores porque, como éstos en el mundo de la química, tenemos inscritas en nuestra conformación de cuidadores y sanadores cualidades empáticas, conexiones emotivas con nuestros enfermos, que conectan con flujos de esperanza, alegría de vivir, capacidad de seguir amando, mantenimiento del sentido de la vida,... en ellos.

Como seres humanos estamos hechos para ser cuidados; y como seres humanos adultos y coherentes, estamos hechos para cuidar a los otros congéneres que se nos aparecen como débiles, limitados, precisados de acompañamiento ( genéricamente: niños, enfermos, limitados, ancianos, terminales ).

Pero hay un periodo de la vida de nuestros semejantes, y de nuestros enfermos, en los que parece se nos hace más cuesta arriba el acompañamiento: ante la terminalidad o el final de la vida.

A lo largo del periodo de mi tarea profesional como clínico, como el que se inclina ante el enfermo, como el que está a los pies de la cama del enfermo, como el que comparte afectos y emociones con el enfermo y su familia, fui aprendiendo a solventar las dificultades que percibía en mi, e intuía en otros compañeros, para acercarse a estos enfermos y sus familias, afrontando tres líneas de acción: con información, con formación y con valentía, experimentando en un segundo momento los bienes evaluables de tal modo de aproximarse a los diversos escenarios en los que finaliza la vida de las personas.

Los primero que aprendí fue a evitar miedos. Cuando uno se acerca al escenario de la terminalidad o de la agonía, como profesional, uno piensa que se le van a presentar cuestiones para las que no va a encontrar solución plausible; o que se le va a recriminar por no haber evitado alcanzar tal desenlace en el paciente. Pero aprecié por el contrario que las familias siempre, - y siempre es siempre -, agradecen la presencia cercana del profesional en dichos periodos o momentos de la vida. Y descubrí que la mirada profesional al lado de un enfermo terminal o agónico con frecuen- 
"... hay un periodo de la vida de nuestros semejantes, $y$ de nuestros enfermos, en los que parece se nos hace más cuesta arriba el acompañamiento: ante la terminalidad o el final de la vida"

cia discierne acciones, posturas, gestos, iniciativas, ... que mejoran el confort, alivian el malestar, o llenan de sosiego al enfermo y sus cercanos. Facilita el diálogo realista entre el enfermo y su familia; y los familiares entre sí.

Los miedos ante el enfermo terminal o agónico son hijos de las ideologías que desarrollan constructos ideales, fantasmagóricos con frecuencia, alejados de la realidad, cara el final de la vida tal como se da entre la mayoría de nuestros enfermos, vecinos y familiares. En cuarenta años de profesión médica y de cercanía a muchos moribundos, la inmensa mayoría lo han hecho en paz. Sí que he vivido grandes desasosiegos y desarmonías en familias de accidentados. La muerte inesperada desestabiliza mucho el ámbito de los cercanos y ahí, también, el profesional de la salud tiene un lugar como catalizador de un duelo que no dañe aún más a las personas.

Nuestra época, al menos en el mundo occidental, es proclive a evitar la idea del morir, a rechazar el proceso en que esta deviene, a ocultar la muerte y a poner la esperanza en un mundo en que no acaezca. Pero la evidencia estadística nos dice, hoy por hoy, que el morir es un evento que acaece en todos los seres en el cien por cien de los casos. ¿cómo no cuidar en este trance?

Un segundo aprendizaje importante fue el aprender a centrar el diagnóstico. A veces, nos da miedo calificar una situación clínica de terminal; parece como si no lo estuviéramos intentando, como si cejásemos en el empeño de lograr la salud. Pero reconocer, como clínicos, en que momento estamos de la historia de la enfermedad y del pronóstico de vida del enfermo, es hoy una evidencia científica cara a proponer las terapias adecuadas al momento clínico y evitar por una parte desahucios, y por otra, evitar iniciar caminos de encarnizamiento o de no adecuación terapéutica.

Hemos vivido en estas últimas décadas acercamientos científicos muy útiles para definir y poner en claridad juicios que facilitan la toma de decisiones clínicas en este sentido. Todavía nos cuesta trabajo asumir los criterios que definen al enfermo agónico, el inicio de tal proceso y nuestra conducta profesional al respecto. Pero sólo estando al lado de nuestros enfermos en el momento de su agonía se nos abren los ojos para discernir; sentimos nuestras emociones y capacidades para acompañar; y nos llenamos de cotas inesperadas de realismo vital y de sabiduría clínica.

Eso nos capacita para ayudar a vivir a los enfermos hasta el último momento (Me expreso como médico clínico y no como teórico de la Bioética). Este ha sido el capítulo que más dinamismo ha dado a mi ánimo profesional médico: descubrir que los enfermos tienen derecho a vivir con gozo en este periodo de sus vidas, que tienen tareas a realizar y con frecuencia tareas pendientes que les llenan de plenitud vital cuando alcanzan a conseguir su logro antes de finalizar su vida.

Tomar sentido de lo que me está sucediendo en el seno de mi enfermedad terminal, no desesperar en el camino; continuar dialogando con mis interlocutores y teniendo relaciones amistosas con mis próximos; amando a los míos; comunicando mis miedos, mis ansias, mis esperanzas y mis alegrías; rehaciendo relaciones rotas con anterioridad, recuperando cercanías con los alejados; perdonando y pidiendo perdón de los errores cometidos; manteniendo el sentido de mi vivir a pesar de la evidencia de su caducidad y, si es posible, estar abierto a una trascendencia bondadosa a la que me puedo entregar confiadamente, ... son tareas en las que merece la pena ocuparse en esta etapa última de la vida. Que nadie robe a nuestros pacientes terminales el deseo de vivir. Que como profesionales, seamos catalizadores de esperanza hasta el final.

Y si algún día las leyes en nuestro estado permiten a los ciudadanos tomar decisiones sobre el final de sus vidas, que este final no sea elegido motivado por un déficit de atención de los profesionales o de la calidad humana de los mismos. 